\title{
Risk Assessment Techniques for Split Capital Investment Trusts
}

\author{
Andy Adams and James Clunie \\ The Management School \\ University of Edinburgh \\ William Robertson Building \\ 50 George Square \\ Edinburgh \\ EH8 9JY
}

May, 2003

\begin{abstract}
The split capital investment trust crisis has brought into focus the need for more reliable risk assessment techniques for shares in the sector. We discuss the strengths and weaknesses of traditional pricing and risk description measures for split capital investment trusts (e.g. gross redemption yield, cover, hurdle rates) and ways of making these more useful. We then examine alternative pricing and risk assessment techniques (e.g. option pricing, sensitivity measures). In particular, some of the problems with the application of traditional option pricing techniques are discussed and methods for dealing with them suggested. We propose the use of stochastic modelling for both pricing shares and understanding their risks.
\end{abstract}

\section{INTRODUCTION}

Split capital closed-end funds ${ }^{1}$ ('splits') may be defined as investment companies or investment trust companies ${ }^{2}$ ('trusts') with more than one main class of share capital, offering different rights to income and capital. ${ }^{3}$ Their assets consist of a portfolio of shares or other securities. They are designed to meet simultaneously the needs of different types of investor. Ultimate responsibility

\footnotetext{
${ }^{1}$ A closed-end fund has a fixed number of issued shares, apart from subsequent share issues or buy-backs.

${ }^{2}$ An investment company can become an investment trust company by complying with the requirements of Section 842 of the Income and Corporation Taxes Act 1988. One requirement is that the company must be listed on the London Stock Exchange. An investment trust company is exempt from tax on capital gains realised within its portfolio.

${ }^{3}$ In everyday usage, the term 'split' is often taken to include other closed-end funds that have high levels of bank debt.
} 
for running the affairs of the company lies with the Board of Directors but day-to-day administration and investment management are normally delegated to an investment management company. Splits are designed to be wound-up at some future date, with most splits having an original term of seven to ten years. ${ }^{4}$ If the company is wound up, its assets are sold and the proceeds are used to pay off the various classes of share capital after meeting the entitlements of holders of debt, if any. ${ }^{5}$

The first modern-day split ${ }^{6}$, Dualvest, was launched in May 1965. The ordinary share capital of this trust was split into two distinct categories - income shares and capital shares. Holders of income shares were entitled to all the distributed income and a predetermined capital value on liquidation. Thus, they received a much higher yield than that on the underlying portfolio, since they were also entitled to the income arising from the capital shareholders' interest in the trust. Holders of the capital shares received no income but were entitled to the remaining assets on liquidation after the income shares had been redeemed. Thus, they obtained geared capital growth. The success of Dualvest led to the creation of a number of similar vehicles, which would all be known nowadays as 'traditional splits'.

In October 1987, Scottish National Trust reorganised into a split with certain novel features. In particular, a more aggressive structure was created by the inclusion of zero dividend preference shares (ZDPs). This was the first time ZDPs (often known as 'zeros') had been issued by an investment trust. ZDPs pay a pre-determined capital sum when the trust is wound up before any distribution of capital can be made to other lower-ranking shareholders. They provide gearing to the lower-ranking shareholders but the cost to the company is not charged to the revenue account. Thus the interest cost effectively rolls up, allowing higher dividends to be paid to other shareholders. ZDPs have no entitlement to income so that, importantly, there is no liability to income tax for the investor.

ZDPs offered flexibility when designing capital structures and became popular in the late 1980s with the rise of a new type of split (sometimes known as a 'quasi-split'). In its simplest form, this type of split has on the liabilities side of its balance sheet, two classes of share - ZDPs and

\footnotetext{
${ }^{4}$ Since 1997, there has been a trend towards 'undated splits' in which the ordinary shares are undated. This has been made possible by issuing zero dividend preference shares via a subsidiary company.

${ }^{5}$ Shareholders always have the option to take cash but in practice, the directors and managers often try to retain the funds under management by encouraging roll-over into another trust or restructuring, rather than liquidation. Indeed, they are all but certain to offer a roll-over option for capital gains tax purposes.
} 
'income \& residual capital shares' (also known as 'ordinary income shares'). The assets side of the balance sheet might simply consist of a broad portfolio of UK equities with an above average yield. When the company is wound up, ZDPs are repaid first. The income \& residual capital shares are designed to offer high income plus all the remaining assets at the wind-up date after the ZDPs have received their capital entitlement. Quasi-splits avoided some of the conflicts of interest that could arise in traditional splits $^{7}$ and were sensible structures from a taxation perspective. Issues of this type of split were common right up to 1997.

With the marked fall in interest rates over the second half of the 1990s, the quest for income among private investors provided an opportunity for the issue of innovative income products (see Adams, 2003). In satisfying this demand for yield, the product providers used various devices that led to the creation of complicated, unstable trust structures. These devices included:

- Substantial levels of bank debt financing. It was considerably cheaper to finance gearing through bank debt rather than through $\mathrm{ZDPs}^{8}$ so bank debt became increasingly useful in creating competitive income products. But the inclusion of bank debt in a split's capital structure meant that, in the event of a breach of covenant, the bank had the right to foreclose and demand either early repayment (in full or in part, with breakage costs), restructuring of the underlying portfolio or dividend freezes/reductions.

- Investment in the income-bearing shares of other splits. Significant proportions of the income shares and income \& residual capital shares in the new issues of splits were typically placed with other splits (hence 'cross-holdings'), thus helping them to meet their own yield requirements. Apart from the problems of accountability and transparency, this generally created gearing upon gearing within the structures.

The above digressions from prudent practice were often combined with a thematic investment strategy in the so-called 'barbell' investment trusts (Adams \& Angus, 2001). The first of these, Technology \& Income Trust, was launched in July 1999 and many of the new issues of trusts in the following two years were of this novel barbell type. Barbell trusts held two distinct portfolios

\footnotetext{
${ }^{6}$ Subdivided capital structures were a feature of trusts as long ago as 1873 (Newlands, 1997).

${ }^{7}$ The pursuit of high income tends to result in lower capital growth.

${ }^{8}$ During the period of falling interest rates, the GRY on a typical ZDP remained high, at say $9 \%$ p.a., whereas bank debt finance could be arranged at perhaps $6.5 \%$ p.a.
} 
of investments - an income portfolio and a growth portfolio ${ }^{9}$. The income portfolio typically consisted of bonds with varying degrees of risk together with the income shares of other splits. The 'growth' portfolio was typically invested in a sector or market that was popular at the time of issue (such as technology stocks).

The new wave of splits had a variety of different capital structures that could include bank debt, ZDPs, income shares, income \& residual capital shares, capital shares or other classes of shares. The shares were generally difficult to value and analyse, and investors often significantly underestimated the downside risk.

\section{TRADITIONAL RISK ASSESSMENT STATISTICS}

In this section we discuss the traditional risk assessment and valuation statistics for four classes of shares that are commonly found in splits: ZDPs, income \& residual capital shares, income shares and capital shares. These statistics are produced routinely by stockbrokers and other financial practitioners. $^{10}$

\section{Zero dividend preference shares}

The main statistics used by financial analysts in assessing the risk of ZDPs, ever since they were first issued in 1987, have been asset cover and hurdle rate.

Asset cover (also known as final asset cover or just cover) is the ratio of gross assets to the assets required to pay the predetermined redemption amount of the ZDPs (and any prior ranking capital) at the redemption date. In a simple split trust with no prior ranking capital and invested in a broad portfolio of UK equities, it gives a rough indication of the risk of the ZDP shareholders not receiving their full entitlement at redemption but does not take the term to redemption into account. It can be defined in different ways. Some analysts, for example, deduct future annual costs charged to capital (management fees, interest charges) in arriving at the total assets figure.

\footnotetext{
${ }^{9}$ In pictorial form this asset structure can look like a 'barbell' such as is used in weightlifting: assets are held at either end of the income/growth spectrum, with nothing in the middle.

10 One of the most comprehensive and timely sources of such data is the "Splitsonline" site (www.splitsonline.co.uk) from Fundamental Data Ltd., which provides daily analysis of split capital investment trusts.
} 
Hurdle rate (also known as fulcrum point or growth to cover) is the required annual growth rate of gross assets to pay the full redemption amount of ZDPs. A negative hurdle rate indicates that gross assets could fall each year by the rate indicated and still be sufficient to repay the ZDPs in full. Hurdle rate is a crude measure of the risk even for a simple quasi-split structure because it does not take into account the yield on the underlying portfolio of assets. Clearly, the higher the yield on the underlying portfolio, the more difficult it is in general to achieve the required annual capital growth rate, as higher yielding securities do not necessarily have higher total returns than lower yielding securities. Hurdle rates generally take future annual costs charged to capital into account. As with asset cover, however, care needs to be taken to establish exactly which definition has been used in the calculation.

A variation on hurdle rate is wipe-out rate which measures the annualised rate of decrease in gross assets that would just lead to no capital payment (or 'wipe-out') on wind-up. This provides a more useful guide to downside risk. Hurdle rate to current share price is another such variation.

Gross Redemption Yield (GRY) is the internal rate of return of the ZDP, before any tax, based on the assumption that it is held to redemption and redeemed in full. The GRY of a ZDP can be compared to that of a British government bond ('gilt') of similar duration. ${ }^{11}$ Thus, Points over Gilt GRY gives a measure of the risk premium priced into a $\mathrm{ZDP}^{12}$. GRY no growth measures the GRY of a ZDP on the assumption that the capital value of the underlying gross assets remains unchanged between the present time and wind-up.

Plots of GRY or GRY no growth against cover or hurdle rate attempt to compare possible returns for ZDPs against some measure of risk.

\footnotetext{
${ }^{11}$ Duration is the weighted average of the times to the cash flows from the security, where the weights are equal to the present values of the cash flows.

${ }^{12}$ There is a slight tax element as well as a risk premium in the yield differential. The majority of investors in ZDPs are, directly or indirectly, private investors who receive tax-free returns from ZDPs, because the returns are treated as capital gains that can be offset against the investor's annual CGT exemption allowance. The majority of gilts are held by institutions and taxed on a different basis, so the yield differential understates the perceived risk of ZDPs.
} 


\section{Income shares}

Key statistics for income shares are asset cover and hurdle rate. The asset cover calculation is based on an income share's full redemption value. Wipe-out rate is also commonly used for income shares.

Net redemption yield (NRY), often used in conjunction with various assumed annual rates of growth of dividends and gross assets, measures the annualised return to income shareholders net of income tax. The range of NRYs for different assumed rates of growth can be useful in risk assessment.

$\underline{\text { Income \& residual capital shares }}$

Hurdle rate, wipe-out rate and net redemption yield are also used for income \& residual capital shares. Gearing is used as a risk measure and may be defined as the ratio of gross assets to the assets attributable to income $\&$ residual capital shareholders.

\section{$\underline{\text { Capital shares }}$}

If there are ZDPs in issue, the normal practice of "stepping up" the ZDP by a pre-determined periodic amount, instead of taking the full redemption value, complicates measurement of the net asset value of capital shares. As a result, Newlands (2000) describes quoted discount to NAV figures for capital shares, a popular valuation method, as virtually meaningless.

As with income \& residual capital shares, hurdle rate, wipe-out rate and gearing are used as risk measures for capital shares.

\section{Why Traditional Risk Assessment Measures Became Misleading}

Following the collapse of many of the aggressively structured splits issued in the late 1990s and beyond, it should now be clear to all investment practitioners that statistics such as asset cover and hurdle rate should not have been used in isolation. Other factors such as the quality of the underlying portfolio of assets, capital structure, expense structure, portfolio volatility and, 
critically, the amount of bank debt and details of bank covenants should have been considered, if such information was available or could have been obtained.

Hurdle rates for shares in the aggressively structured trusts appeared deceptively easy to achieve, for the following reasons:

- Hurdle rates are based on growth of the whole underlying portfolio, ignoring the fact that a substantial part of the portfolio may not be held in growth assets and thus could not possibly be expected to grow at anything like the projected rate of growth of the growth assets.

- Investors' expectations of returns from equities had been derived from the bull market of the previous quarter of a century.

- Many investors were unaware that the expected nominal return on equities will be low in an environment of low inflation and low interest rates. If there were holdings in the highyielding shares of other splits, with dividend yield exceeding expected total return, it was in fact reasonable to expect erosion in their capital value.

- Any holdings in high-yielding bonds could suffer defaults and capital loss.

The last two reasons also made the asset cover statistic misleading. This statistic was even more misleading if the trust's costs up to maturity were not deducted from gross assets.

It is possible to find two ZDPs with similar hurdle rates and cover but with very different risk profiles. Appendix 1 presents a hypothetical case of a geared ZDP with equal hurdle rate and superior cover to an ungeared ZDP, but with greater sensitivity to large falls in the underlying asset portfolio.

\section{Making Traditional Statistics More Useful}

We have shown that traditional risk measures can be dangerously misleading in certain circumstances. However, there are ways in which they can be made more useful. 
Total return to cover could be used instead of hurdle rate. It represents the total return (i.e. capital gain plus dividend yield) required on the underlying portfolio of assets for the ZDP to reach a cover of 1 . The total return to cover can be compared with the expected return on the total underlying portfolio, to gauge whether or not full payment of the ZDP or income share redemption amount is realistic. Another variation on hurdle rate would be to measure the hurdle rate (or total return to cover) on that part of the underlying portfolio invested in growth assets. This would present a more realistic picture of the growth required on the growth assets within a 'barbell' trust.

Greater use of sensitivity analysis, showing GRY or NRY for various negative and positive total return scenarios (e.g. $-10 \%$ per annum, $-5 \%$ per annum, $\ldots,+15 \%$ return, $+20 \%$ per annum) would aid understanding of the risks involved for a particular class of shares. It is important that a number of negative market scenarios are included in any such analysis. A plot of GRY (\% per annum) against Percentage Change (per annum) in the Underlying Portfolio, such as shown in Appendix 1, would also aid in the assessment of risk for a class of share.

As cross-holdings in other splits can increase risk, classifications of trusts by percentage of gross assets held in splits and high yield funds have been launched (see Appendix 2 for one such classification system). Further refinements include rating systems based on both cross-holdings and proportion of gross assets represented by debt. These systems are generally crude, and could be improved by analysing the quality of the underlying securities held, rather than treating all investments in splits and high yield funds as equally risky. These ratings also refer to trusts rather than classes of shares within a trust.

A more developed approach (Merrill Lynch, 1999) to describing risk for a ZDP is to assign 'credit ratings' to ZDPs, as with non-government bonds. This involves estimating the probability of default and the returns expected on default. Comparing these numbers with the historical experience of a range of bonds with different credit ratings, a credit rating can be assigned to the ZDP. Finally, an appropriate credit spread can be determined for each rating by reference to the bond market ${ }^{13}$. The anticipated spread is then compared to the 'Points over Gilt GRY' to see if risk is appropriately priced. This approach takes account of the probability of default, so is generally more useful than traditional risk assessment statistics. It can also be used to explain the

\footnotetext{
${ }^{13}$ Strictly speaking, the slight tax element in the yield differential should be taken into account.
} 
ZDP market's behaviour at times when bond market credit spreads widen. An example of this was the widening of ZDP credit spreads during the 1998 LTCM/ Russian bond crisis.

\section{SENSITIVITY MEASURES FOR RISK ASSESSMENT OF SPLITS}

Adams (1999) proposed the use of 'sensitivity measures' in the risk assessment of splits. These are derived by differentiating formulae for the discounted cash flows of a particular security with respect to the underlying fundamental variables. Thus, they show how the present value of expected future cash flows will vary as the fundamental variables that determine the present value vary. They are an extension of the concept of duration, which is commonly used for fixed-income bonds and has also been applied to the analysis of equities. But the analysis is valid for sensitivities to factors other than nominal discount rate. Sensitivity measures can be calculated with respect to all the underlying fundamental variables, whether these be real variables or nominal variables. To simplify the mathematics, the formulae are derived in continuous time rather than in discrete time, with continuous forces for the underlying fundamental variables. For split capital investment trusts, these fundamental variables will include the estimated force of inflation, the real discount force, and the estimated real growth force of both dividends and the underlying fund.

We define sensitivity to variable $k$ as:

$S_{k}=\frac{\partial V_{0}}{\partial k} \cdot \frac{1}{V_{0}}$

where $V_{0}$ is the present value of the investment.

Sensitivity to variable $k$ can be thought of as the percentage change in the present value of the investment per one percentage point change in variable $k$, for small changes in variable $k$.

As an illustration, consider a traditional split with no debt and with the capital shares deep-in-themoney. The sensitivity to the force of inflation for the capital shares is given by: 


$$
S_{\phi}=\frac{m R}{A_{0} e^{(\zeta+\phi) m}-R}
$$

where: $\phi$ is the estimated force of inflation per annum.

$m$ is the period in years before the income shares are redeemed.

$R$ is the redemption amount for each income share after $m$ years.

$A_{0}$ is the value of the fund at time 0 per capital share.

$\zeta$ is the estimated real force of growth per annum of the fund.

Sensitivity measures are useful in comparing the risk of different securities in splits. But the following should be borne in mind:

(i) The importance of a given variable in influencing the present value of a particular security over time depends not only on the sensitivity measure with respect to that variable but also on the volatility of that variable itself over time. Thus, although the sensitivity measure for a particular security with respect to variable $k$ may be relatively low, if variable $k$ is extremely volatile over time, it may still have an important influence on changes in the present value of that security over time.

(ii) The sensitivity measures are all partial, and do not allow for the fact that the various determinants may be interdependent. For example, real force of discount may tend to fall as expected inflation rises.

Sensitivity measures are helpful when capital shares (or income \& residual capital shares) are deep-in-the-money. However, they are of little use when the capital shares are out-of-the-money and thus have non-negligible time value. An option pricing approach is more suitable in such circumstances.

\section{OPTION PRICING}

Ingersoll (1976) studies US dual purpose funds ${ }^{14}$, which are similar to UK traditional splits, and creates a framework that can be used for pricing the components of UK split capital investment

\footnotetext{
${ }^{14}$ Dual Purpose Funds are a form of US closed-ended fund, now extinct following a change to the US tax code in 1989.
} 
trusts. Litzenberger \& Sosin (1977) discuss the structure and management of US dual purpose funds. There are two classes of shares with claims on the same underlying portfolio: firstly, income shares, which have the right to any income that the fund may earn, subject to a minimum cumulative dividend, and are redeemable at a set price at the maturity of the fund; and, secondly, capital shares, which pay no dividends and are redeemable at the residual value of the fund at maturity after redemption of the income shares.

To derive an appropriate option pricing model, Ingersoll makes the following assumptions:

- Capital markets are perfect in that there are no differential taxes or transaction costs; assets are perfectly divisible; investors act as price takers; there is unlimited borrowing or lending at the risk free rate of interest; there are no restrictions on short selling.

- Trading takes place continuously in time.

- The asset value $(V)$ of the dual purpose fund satisfies the stochastic differential equation:

$$
d \mathrm{~V}=(\alpha \mathrm{V}-\mathrm{C}) d t+\sigma \mathrm{V} d z
$$

where: $\mathrm{C}$ is the total cash paid out per unit of time.

The pay-out policy is non-stochastic.

Future values of $\mathrm{C}$ need not be certain, but must be known conditionally on knowing $\mathrm{V}$.

$\alpha$ and $\sigma^{2}$ are the instantaneous expected rate of return and the variance of return on the underlying assets.

The variance rate is non-stochastic and at most a known function of time.

$d z$ is a Gauss-Wiener process.

The term structure of interest rates is flat and non-stochastic.

$\sigma^{2}$ is a constant.

Dividends $D$ are paid continuously to the income shares and are proportional to the asset value, so that $D=\delta V$, where $\delta$ is a constant.

Management fees $M$ are paid continuously and are proportional to the asset value, so that $M=\mu V$, where $\mu$ is a constant.

$C=(\delta+\mu) V=\gamma V$ 
Ingersoll then applies research by Merton (1973 and 1974) to derive pricing functions for both the capital shares and the income shares.

The capital share price is given by:

$f(V, \tau)=E \mathrm{e}^{-r t}\left\{Z N\left(x_{1}\right)-N\left(x_{2}\right)\right\}$

where: $\tau$ is the number of periods of time to maturity of the fund.

$E$ is the redemption price of the income shares.

$r$ is the instantaneous rate of interest.

$$
\begin{aligned}
& Z=V \mathrm{e}^{(r-\gamma) \tau} / \mathrm{E} \\
& x_{1}=\left(\log Z+\sigma^{2} \tau / 2\right) / \sigma \sqrt{\tau} \\
& x_{2}=x_{1}-\sigma \sqrt{\tau} \\
& N(x)=1 / \sqrt{2 \pi} \int_{-\infty}^{x} e^{\left(-s^{2} / 2\right)} d s, \text { the cumulative standard normal distribution. }
\end{aligned}
$$

Income shares are considered to consist of two separable claims: one on the dividend stream, the other on the final redemption payout.

The pure dividend claim has the value:

$V(\delta / \gamma)\left(1-\mathrm{e}^{-\gamma \tau}\right)$

The redemption claim has the value:

$\mathrm{e}^{-\gamma \tau} V-f(V, \tau)$

Drawing on this research, Gemmill (2002) shows that a ZDP may be considered equal in value to the present value of a risk-free bond less the value of a put option on the trust's gross assets. The exercise price of the put equals the sum of the payments due at maturity on prior charges and the bond. Prior charges are assumed to be risk free. Given that lenders are able to place covenants on their loans (e.g. assets to exceed debt by 1.8 times) and demand borrowers take action to reduce 
risk if the covenants are breached, the risk of making such loans is certainly low. However, difficulties in liquidating portfolios following a covenant breach may in practice lead to losses, and a risk premium is understandably priced into the loans when originated ${ }^{15}$.

Denoting the theoretical price of a ZDP by $Z$, we have:

$Z=F_{z} /(1+r)^{T}-\operatorname{Put}\left(P+F_{z}\right)$

where: $r$ is the appropriate annualised rate of interest taken from the risk-free zero coupon yield curve.

$T$ is the time to maturity in years.

$F_{z}$ is the final redemption value of the ZDP.

$P$ is the sum of the payments due at maturity on prior charges.

$\operatorname{Put}(X)$ denotes the theoretical value of a put option with strike price $X$ and with expiry date equal to the wind-up date of the trust.

Appendix 3 shows the payoff chart for the ZDP.

In applying the Black-Scholes (1973) model to determine the price of the put option, certain inputs must be calculated, observed or estimated:

- Exercise price is known (sum of any prior charges and the final ZDP payment).

- Interest rate $r$ is defined above.

- Yield may be estimated as the gross revenues from the underlying portfolio less costs attributable to the revenue account, divided by the gross assets.

- The value of the underlying gross assets could be obtained from the trust managers, or estimated from NAV, adjusted for prior charges, capitalised charges and management fees.

- Volatility of the underlying gross assets can either be estimated from historical norms, forecasted, or derived from a history of the level of gross assets, if available.

In developing an option pricing model for other classes of shares, we will confine our attention to splits with a bank loan, ZDPs, income shares and capital shares. Traditional and quasi-splits

\footnotetext{
${ }^{15}$ Data on the losses suffered by banks on such loans have not been made public to date.
} 
effectively represent special cases of this type of structure. In the case of a traditional split, there are no ZDPs in issue; in the case of a quasi-split the income shares and capital shares are combined as a single class of share.

Income shareholders are entitled to all the dividends paid out by the trust, plus a final redemption value on wind-up if sufficient assets are available. Dividends are generally set in advance, but managers have increased, cut or cancelled dividends in the past.

The theoretical price of an income share, $I$, is given by:

$I=\sum_{t=1}^{T} \mathrm{E}\left(D_{t}\right) /(1+r)^{t}+F_{i} /(1+r)^{T}-\operatorname{Put}\left(P+F_{z}+F_{i}\right)+\operatorname{Put}\left(P+F_{z}\right)$

where: $F_{i}$ denotes the final redemption value of the income shares.

$\mathrm{E}\left(D_{t}\right)$ denotes the expected value of the dividend to be paid to income shareholders at time $t$.

The payoff chart for the income share is given in Appendix 4.

Capital shareholders are entitled to the residual assets once all prior capital has been paid. The payoff for the capital shares can be represented as:

$\operatorname{Max}\left(A-\left[P+F_{z}+F_{i}\right], 0\right)$

where $A$ is the final gross asset value of the trust.

Thus, the theoretical price of a capital share, $C$, is given by:

$C=\operatorname{Call}\left(P+F_{z}+F_{i}\right)$

The payoff chart for the capital share is given in Appendix 5. 
Sensitivity measures (known as 'Greeks' - delta, kappa etc) can be derived from the BlackScholes model (see Hull, 2003). One use of these Black-Scholes sensitivities from the perspective of a manager of a split would be in marginal contribution analysis. Prior to the disposal or purchase of a security, the change in volatility of the gross assets could be estimated, and the consequent effect on the price of shares in each class deduced by calculating kappa. Note that some of the fundamental variables considered by Adams (1999) in the risk assessment of splits are not explicitly present in the Black-Scholes model. The Black-Scholes model sensitivities thus have limited use in the risk assessment of splits.

\section{PROBLEMS WITH CURRENT OPTION PRICING MODELS FOR SPLITS}

Existing option pricing models for splits make a number of simplifying assumptions. Factors that reduce the effectiveness of such models include:

- Possible variation in the management and administration fees (for example, some trusts have negotiated reductions in fee levels in recent years). Also, expense allocation policy could be changed $^{16}$, thereby changing the value of different classes of share.

- Gross asset volatility must be estimated. The net asset value of a split is published periodically, but it is the volatility of the gross assets (i.e. net assets plus debt, including bank loans) that is the required input for the model. Gross asset volatility may vary over time, due to either changing market conditions or adjustments to portfolio holdings by the investment manager. Stochastic modelling techniques for gross asset volatility have been developed and these can help with this problem. For example, Scott (1997) presents an option pricing model with stochastic volatility, stochastic interest rates and a jump-diffusion process driving stock returns. Both volatility and interest rates are assumed to be correlated with stock returns in the model.

- The possibility of changes to income share distributions and the impact of this on other share classes. Such changes may be due to the Board's discretion over distributions. In addition, Section 265 of the Companies Act 1985 states that dividends must not be distributed if the

\footnotetext{
${ }^{16}$ The Statement of Recommended Practice for the Financial Statements of Investment Trust Companies (AITC 1995) recommends that: 'Investment management fees should be allocated between capital and revenue in accordance with the board's expected long-term split of returns, in the form of capital gains and income respectively, from the entire investment portfolio of the investment trust company'.
} 
gross assets of a trust are less than 1.5 times the trust's liabilities ${ }^{17}$. To forecast future dividends, it is helpful to know historical income share distributions and to understand how distribution changes are decided by the Board. Understanding can be assisted through knowledge of the trust's articles of association, the Board's method of achieving fairness between the different share classes, the revenue reserves and the yield on the underlying asset portfolio. An algorithm could then be created to model the Board's behaviour and this could form the basis of a modelling approach to the problem.

- Changes in the value of long-term fixed-rate debt within a trust. Many portfolio accounting systems will only account for such loans at face value but 'mark to market' adjustments to the value of loans are appropriate. An adjustment in the value of a loan will be reflected in the gross asset value of the trust.

- Cross-holdings. Several splits own the income-bearing shares of other splits or high-yielding investment companies as a source of higher dividend income. However, the dividends from these holdings may be raised, cut or cancelled, and extreme capital losses are possible as a result. A fall in the value of income-bearing shares in one split may have a resonant impact on other splits due to cross-holdings.

- Banking covenants and possible breaches of those covenants. If a covenant is breached, the lender may require the trust to sell assets to raise cash, thereby restoring the asset to debt ratio to an acceptable level and reducing the risk to the lender. This can create a path dependency problem that makes the use of closed-form or lattice methods of implementing option pricing ineffective. Selling assets to raise cash will also lower the volatility of the underlying asset portfolio, which will have a negative impact on the value of any capital shares, particularly if they are out-of-the-money. Note that banking covenants may be renegotiated during the life of the trust, further complicating the analysis. ${ }^{18}$ Cazenove \& Co (2001) discuss how the interaction of cross-holdings and covenant breaches could lead to a systemic collapse amongst 'barbell' investment trusts.

\footnotetext{
17 There has been at least one breach of this rule. The Chairman's Statement in the Annual Report for Danae Investment Trust PLC (February 14th, 2003) stated: "On 12 December the Board announced that the purchase for cancellation of $14.9 \%$ of the Company's zero dividend preference shares had been ruled an unlawful transaction because on the date of the purchase the company was unable to satisfy Section 264 of the Companies Act."

${ }^{18}$ One example of a renegotiated covenant can be seen in the Chairman's Statement of the Annual Report for Danae Investment Trust PLC (February 14th, 2003), which states: "We are required to maintain cover of $165 \%$ in acceptable assets over the outstanding amount of the loan; however the Bank [of Scotland] has granted us the right to offset cash held within the portfolio against the loan's value for the purpose of that calculation. This has proved an invaluable option."
} 
- Share-buyback programmes. The manager can enhance NAV per share and possibly smooth movements in the discount to NAV (Adams et al, 2002) by buying ZDPs at a discount and cancelling them. A buyback may also change two of the inputs to the option model. Firstly, gross assets per share will rise; secondly, the volatility of gross assets may increase (gearing will increase if there is bank debt or prior ranking capital but no increase in the allocation to cash or bonds following a buyback). As regards ZDP pricing, the increase in gross assets per share is likely to overwhelm the effect of an increase in volatility, although the manager's tactics need to be considered for a full understanding of the impact of buybacks. ${ }^{19}$ Capital shares will clearly benefit from any increase in volatility. However, Section 264 of the Companies Act, which provides a net asset test, may restrict share buybacks.

- Credit spreads are not an explicit input to the ZDP option pricing model, yet certain market events (e.g. sudden large-scale aversion to credit risk) may lead to wholesale changes in credit spreads. A study by Merrill Lynch (1999) showed that a snapshot comparison of a Black-Scholes pricing model to a credit spread pricing model gave a close relationship (Rsquared close to 1). This suggests that both methods offer a valid means of valuing ZDPs. However, there may be times when a credit spread model provides a better explanation of share price movements than an option model and vice versa.

Analyses by Merrill Lynch (1999), Gemmill (2001) and Cazenove \& Co (2002) give a varied picture for the differences between market prices and option model prices for both ZDPs and income \& residual capital shares. An alternative approach is to calculate the implied volatility of each class of share using observed prices and a closed-form option pricing model. Implied volatility can then be compared to peer group implied volatilities or forecast volatilities. 'Unreasonable' implied volatility would suggest mis-pricing.

In practice, option pricing models for splits often allow for the 'marked to market' pricing of debt and the writing-off of certain high-risk cross shareholdings. This approach is combined with an appraisal of the investment manager's performance history and visual interpretation of charts showing annual returns for each class of share for varying levels of growth of dividends or total assets, to gauge the attractiveness, or otherwise, of a particular security.

\footnotetext{
${ }^{19}$ Many managers will sell the 'marginally least attractive' asset in the portfolio at the time of a buy back to finance that buy-back; others may use cash holdings within the portfolio at the time of the buyback.
} 


\section{PRICING AND RISK ASSESSMENT USING MONTE CARLO SIMULATION}

With the complexities of many split structures undermining the effectiveness of current closedform option pricing approaches, the use of Monte Carlo simulation represents a suitable alternative implementation method (Boyle, 1977; Barrie \& Hibbert, 2003). Simulations can deal with many of the problems described above. Potential distributions of dividends and capital payments to each class of shareholder over the lifetime of the trust can then be estimated.

The starting point is to ascertain the structure of the investment portfolio, including percentages held in various asset classes (e.g. equity, possibly broken down by region or sector; bonds, described by coupon, maturity, rating and seniority; income-bearing shares in other splits etc.). The trust's liabilities must then be ascertained, including proportional and fixed fees and their allocation to revenue and capital accounts; loan interest and allocation; corporation tax; loan covenants and rules to be followed if these covenants are breached. The trust's share capital structure is also a required input to the model. Some of the key features of the model are as follows:

- The model incorporates a set of rules for generating asset returns and paying liabilities over each time period.

- Using a stochastic model for equity returns, interest rates and credit transitions, the returns on each of the trust's asset classes are derived. Both capital returns and income are calculated, with income added to the trust's revenue account.

- Fixed expenses and expenses proportional to the underlying gross (or net) assets are charged to the capital and revenue accounts using the specified allocation rule.

- Interest is charged to the capital and revenue accounts using the specified allocation rule.

- Dividends paid by the trust are charged to the revenue account.

- Corporation tax rates are applied to unfranked income, after offsetting the trust's expenses and interest payments.

- Banking covenants are checked and, if breached, portfolio re-allocation is carried out according to a specified covenant breach rule.

- If the test in Section 265 of the Companies Act 1985 rule is not met, dividends that would otherwise have been paid are held in a revenue reserve account for payment if compliance is achieved later. If compliance is not achieved later, this reserve would be distributed as capital if all prior charges have been paid. 
- On wind-up of the trust, capital distributions are made to each class of share according to predetermined rules.

Modelling cross-holdings in a split is a considerable challenge. One approach is simply to treat income-bearing shares as high-beta equities. A more sophisticated approach would be possible if the portfolio holdings data for all trusts in the splits universe could be obtained ${ }^{20}$. It would then be possible to 'drill-down' to the effective underlying holdings for each trust. This approach would present a true picture of the underlying portfolio for each trust, but would be time consuming, even if the required data could be obtained easily.

\section{Using Simulation Outcomes to Illustrate Risk}

Given a series of simulations, a cumulative probability distribution curve for gross assets at the wind-up date can be constructed (see Appendix 6). A chart can also be constructed to show the mean path and, say, the $5^{\text {th }}$ and $95^{\text {th }}$ percentile of paths for gross assets at each stage in the simulation process (see Appendix 7).

A fair value for each share can be estimated from knowledge of the mean redemption values and all dividend payments across the simulations (calculated under the risk-neutral measure). Possible reasons for differences between estimated fair values and current market prices include poor liquidity in the splits market, difficulties in undertaking arbitrage (due to poor splits transparency and difficulties in short-selling), mis-specification of the model, or an investor sentiment effect (e.g. investors shun a segment of the stock market that has been under regulatory scrutiny).

To understand better the risks associated with each class of share, we propose the use of separate 'payoff cumulative probability charts' for each class of share. For each of these charts, the horizontal axis shows the payoff (in Pounds) for the share at wind-up. The vertical axis shows the cumulative probability of such a payoff. Based on the outcomes from a series of simulations, the chart thus shows the probability that the payoff is equal to or less than any given value on the horizontal axis. Figures 1, 2 and 3 illustrate this method, using an asset generating model and the capital structure of a theoretical split, as described in Appendix 8. 

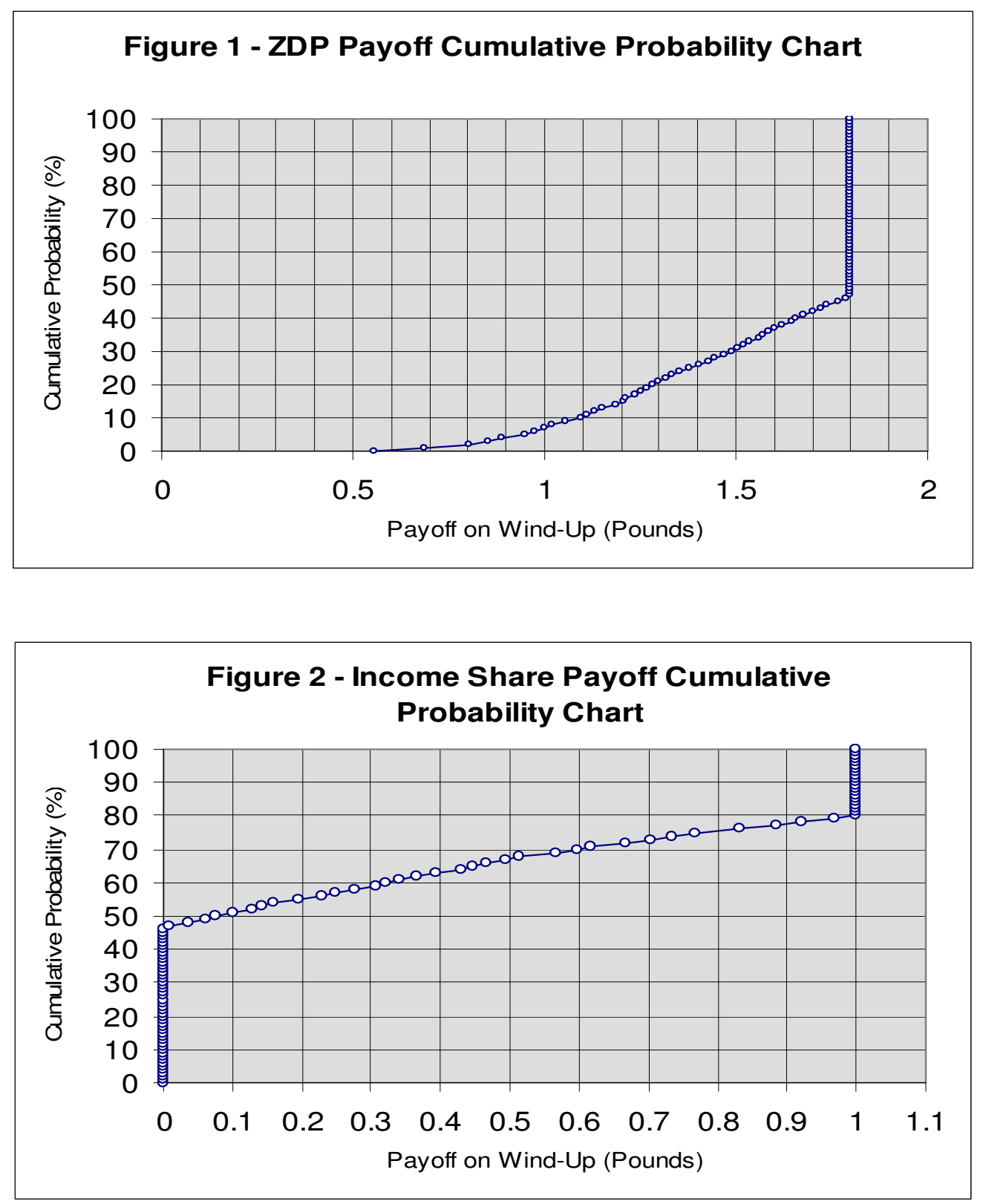

\footnotetext{
${ }^{20}$ The Institute and Faculty of Actuaries' submission (February 2002) to the FSA Discussion Paper 10 argues for greater disclosure than at present, but not to the extent of publishing details of split holdings
} 


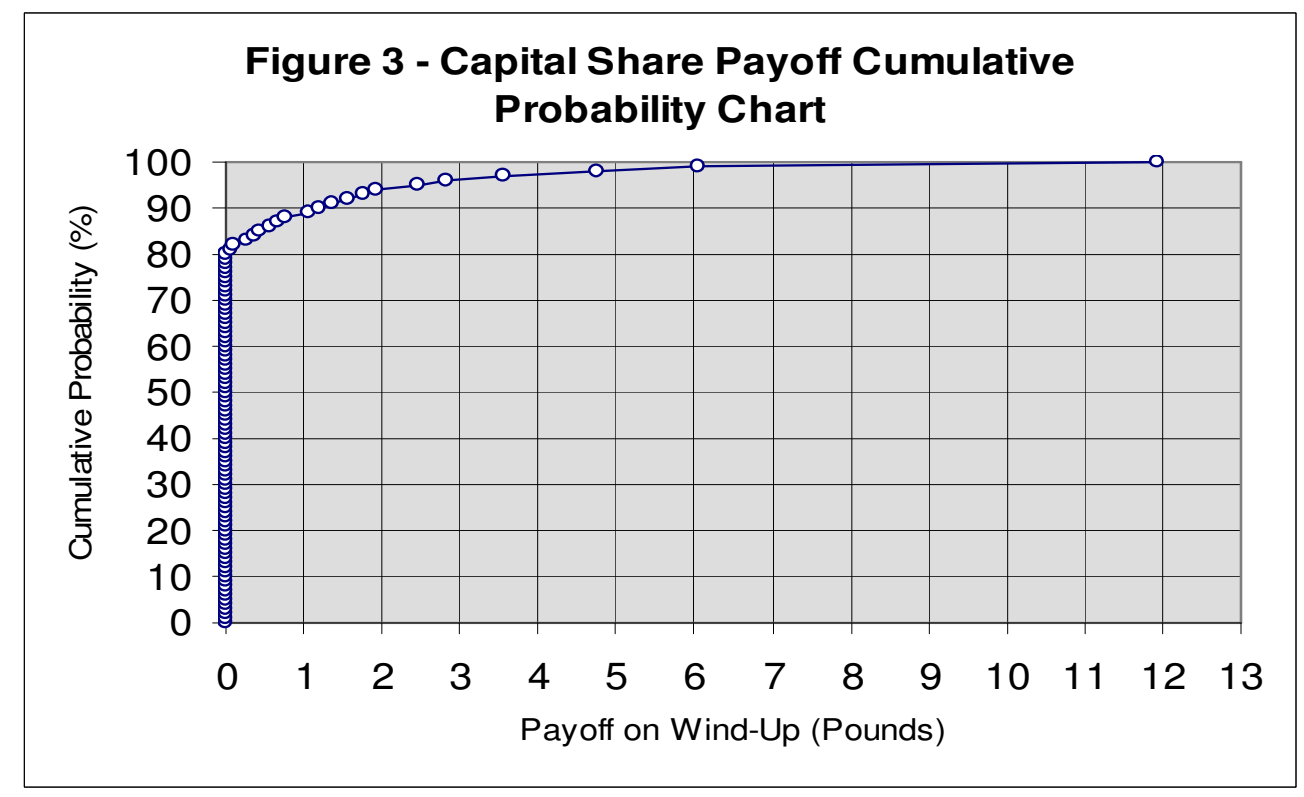

To illustrate risk/ return profiles, we advocate the creation of 'return probability histograms' for each class of share. The annualised returns up to the wind-up date for a class of share are based on the outcome of a series of simulations. The probability associated with each range of returns is calculated as the proportion of simulation returns that fell within that range. For the theoretical split detailed in Appendix 8, the return probability histograms for each class of share are shown in Figures 4, 5 and 6.

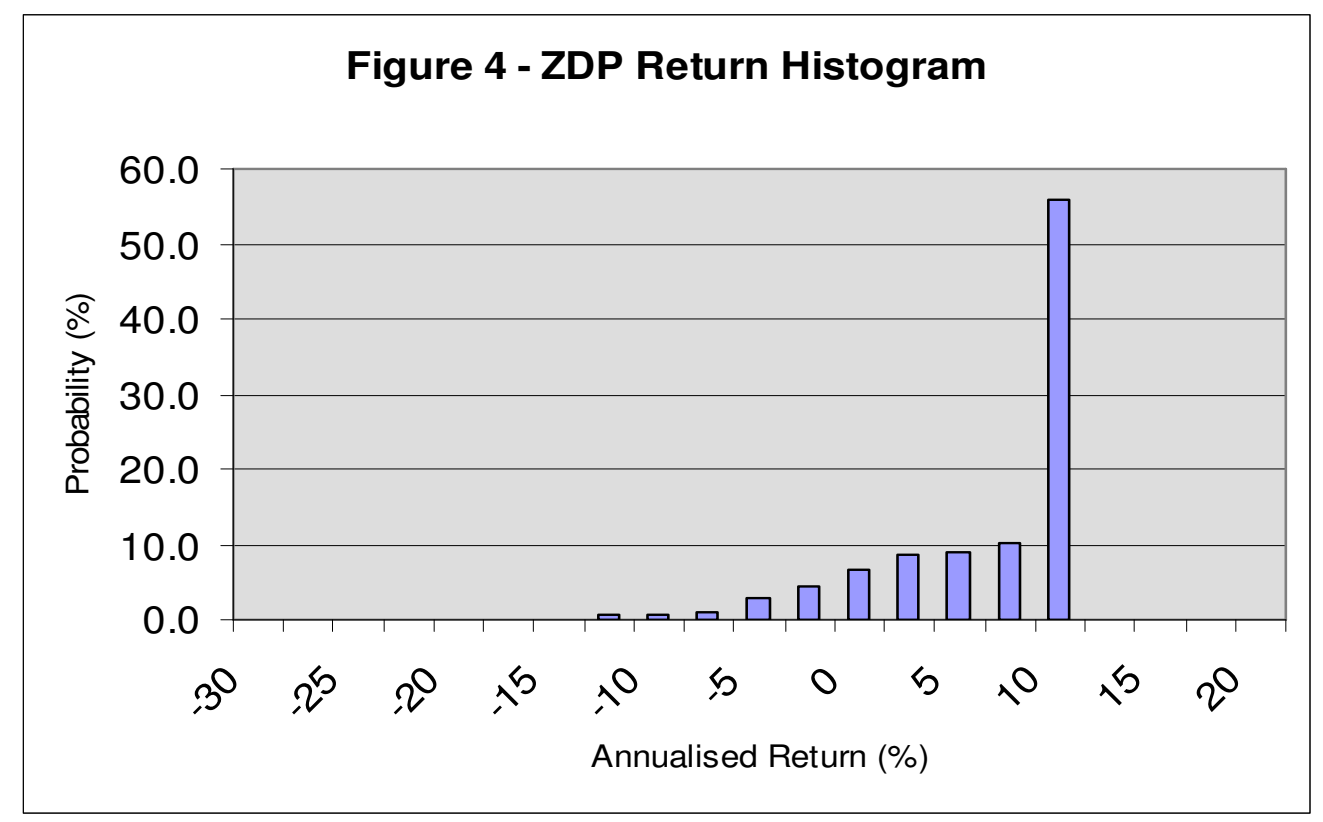

above $0.5 \%$ as proposed by the Association of Investment Trust Companies. 

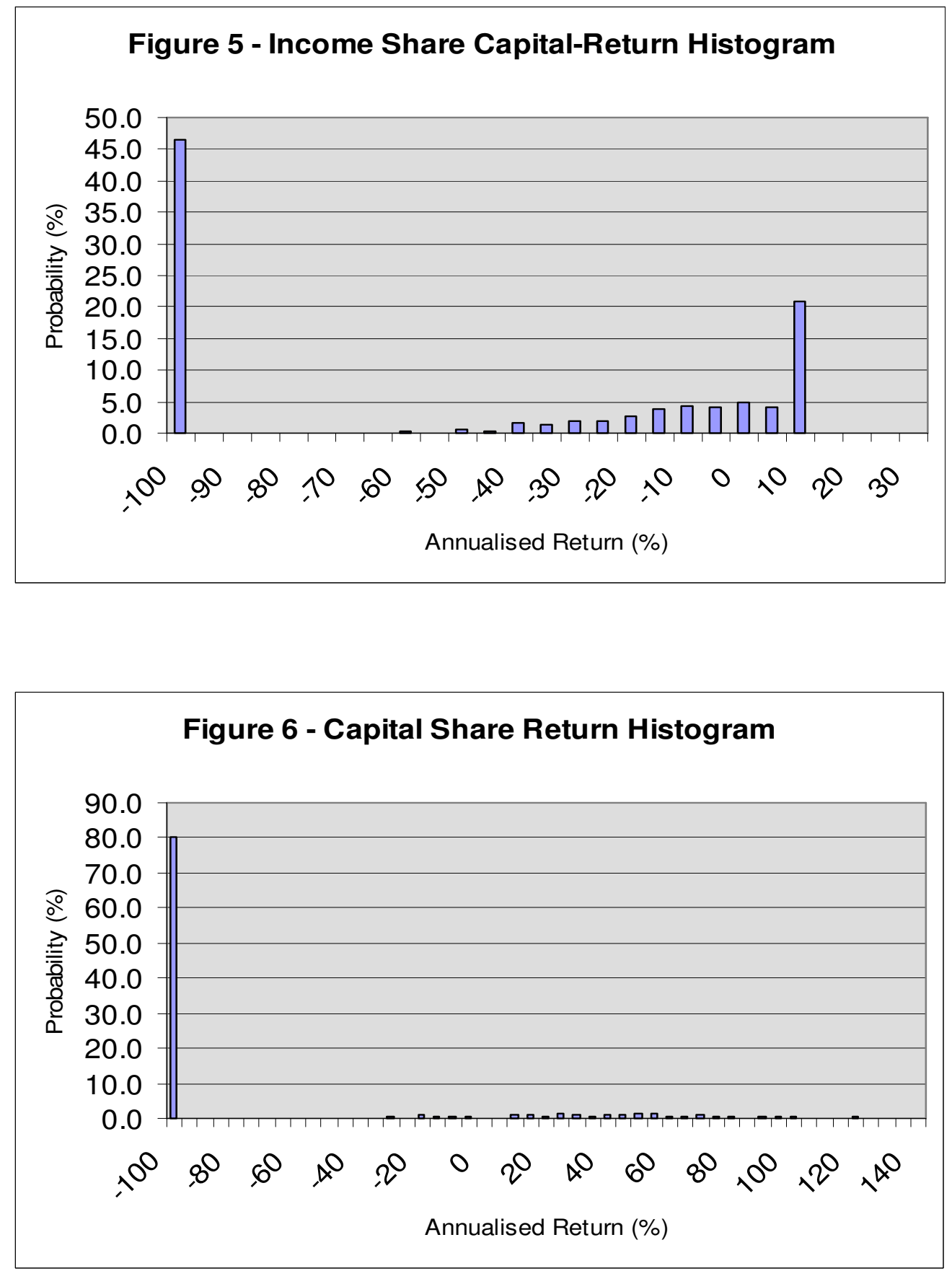

For the income shares, dividends received over the life of the fund should also be considered. Due to the possibly different tax treatment of income and capital, taxable investors may wish to keep income and capital return charts separate. However, the two may be combined to produce a total 
return histogram, using a particular investor's tax rates for income and for capital gains in the total return calculation, if required.

\section{Sensitivity Analysis using Stochastic Modelling}

It is possible to study the sensitivity of the output to different assumptions in the asset-return generating model or to changes in the trust's structure. This helps in understanding the risks involved and may be useful in the design of new splits, as well as in assessing existing splits. It can also be used to complement the limited sensitivity analysis that is possible using closed-form option pricing models. Table 1 illustrates some of the ways in which sensitivity analysis can be applied using simulation techniques, for the theoretical split outlined in Appendix 8.

$\underline{\text { Table } 1 \text { - Sensitivity Analysis Example }}$

\begin{tabular}{|l|l|l|l|l|l|}
\hline & $\begin{array}{l}\text { Initial } \\
\text { State (as } \\
\text { per } \\
\text { Appendix } \\
8)\end{array}$ & $\begin{array}{l}\text { Replace high } \\
\text { yield portfolio } \\
\text { with bonds; set } \\
\text { equity } \\
\text { portfolio } \\
\text { dividend yield } \\
\text { to 4\% from } \\
3.5 \%\end{array}$ & $\begin{array}{l}\text { Alter capital } \\
\text { structure: } \\
\text { replace 5 } \\
\text { million of } \\
\text { ZDPs with } \\
\text { bank loan } \\
(£ 5.5 \\
\text { million) }\end{array}$ & $\begin{array}{l}\text { Replace } \\
\text { f10 million } \\
\text { of equities } \\
\text { with bonds; } \\
\text { set number } \\
\text { of bonds to } \\
20 \text { from 10 }\end{array}$ & $\begin{array}{l}\text { Set equity } \\
\text { risk premium } \\
\text { to 2.5\% from } \\
3.5 \% \text {; set } \\
\text { equity } \\
\text { volatility at } \\
15 \% \text { from } \\
\text { share wipe-out }\end{array}$ \\
$\begin{array}{l}\text { Capital } \\
\text { probability (\%) }\end{array}$ & 80 & 83 & 77 & 85 & $20 \%$ \\
\hline $\begin{array}{l}\text { Probability of capital gain on } \\
\text { capital shares (\%) }\end{array}$ & 17 & 15 & 20 & 13 & 83 \\
\hline $\begin{array}{l}\text { Income share wipe-out } \\
\text { probability (\%) }\end{array}$ & 47 & 44 & 41 & 44 & 40 \\
\hline $\begin{array}{l}\text { Probability of capital gain on } \\
\text { income shares (\%) }\end{array}$ & 30 & 28 & 33 & 25 & 29 \\
\hline $\begin{array}{l}\text { Probability that ZDP pays out } \\
\text { full redemption value (\%) }\end{array}$ & 53 & 56 & 58 & 55 & 59 \\
\hline
\end{tabular}


Sensitivity analysis could be used to create a capital structure at launch, or an asset allocation at any stage in the fund's life, such that the probability of the ZDP paying out its full redemption value meets a certain value (e.g. 95\%). Various share buy-back proposals could also be studied using this technique, to assess the impact on each class of share and thus to ensure fairness across all classes.

\section{CONCLUSION}

As the complexity of split capital investment trusts has increased, with greater use of bank loans tied to covenants and an increase in cross-investment within the sector, so too has the need for more sophisticated risk assessment techniques. The use of traditional measures in such an environment gives a dangerously false sense of understanding of the risks. The applicability of option pricing models and sensitivity measures has also been severely limited by the complexity of many trust structures. We advocate the use of stochastic modelling to deal with these complexities, and suggest the use of simple descriptive diagrams derived from this technique to illustrate the risks inherent in each class of share.

\section{REFERENCES}

Adams, AT, 1999, "Sensitivity Measures for Split-Capital Investment Trusts", IMA Journal of Mathematics Applied in Business and Industry, 10, 347-364

Adams, AT, 2003, "The Split Capital Investment Trust Crisis: Underlying Reasons and Historical Developments", House of Commons Treasury Committee, Third Report of Session 2002-03, Appendix 3, Volume II, 17pp.

Adams, AT \& Angus, R.J., 2001, "For Whom the Barbell Tolls...", Professional Investor, April 2001, 14-17.

Adams, AT, Macpherson, R \& Moretta, B, 2002, "Assessing the Effects of Buybacks on Investment Trust Discounts", Proceedings of the $8^{\text {th }}$ Joint Institute $\&$ Faculty of Actuaries Finance $\&$ Investment Conference, 13pp 
Association of Investment Trust Companies, 1995, "Statement of Recommended Practice."

Barrie \& Hibbert Limited, 2003, "Split Capital Investment Trust Monte Carlo Simulation Model".

Black, F, \& Scholes, M, 1973, "The Pricing of Options and Corporate Liabilities", Journal of Political Economy, 81(3), 637-654.

Boyle, P, 1977, "Options: A Monte Carlo Approach", Journal of Financial Economics, May 1977, 323-338.

Cazenove \& Co., 2001, "Barbells Unbalanced."

Cazenove \& Co., 2002, “Zeros as Options.”

Fundamental Data Ltd, 2003, “Split Capital Closed End Funds Monitor”, www.splitsonline.co.uk

Gemmill, G, 2002, “Testing Merton's Model for Credit Spreads on Zero-Coupon Bonds”, City University Business School.

Gemmill, G, 2001, "Capital Structure and Firm Value: A Study of Split-Capital Closed-End Funds in the UK", City University Business School.

Hull, JC, 2003, Options, Futures \& Other Derivatives, Chapter 14, Prentice-Hall International.

Ingersoll, JE, 1976, "A Theoretical and Empirical Investigation of the Dual Purpose Funds", Journal of Financial Economics, 3, 83-123.

Institute and Faculty of Actuaries, 2002, Response to the FSA Discussion Paper 10: Split Capital Closed End Funds, February $18^{\text {th }}$.

Litzenberger, RH \& Sosin, WF, 1977, "The Structure and Management of Dual Purpose Funds", Journal of Financial Economics, 4, 203-230 
Merrill Lynch, 1999, "Zero Dividend Preference Shares - What are They Worth?”

Merrill Lynch, 2001, "Zero Dividend Preference Shares - Understanding the Risks and How to Price Them."

Merton, RC, 1973, “The Theory of Rational Option Pricing”, Bell Journal of Economics and Management Science, 4, 141-183.

Merton, RC, 1974, "On the Pricing of Corporate Debt: the Risk Structure of Interest Rates”, Journal of Finance, 29, 449-470.

Newlands, J, 1997, Put Not Your Trust in Money: A History of the Investment Trust Industry from 1868 to the Present Day, The Association of Investment Trust Companies.

Newlands, J, 2000, “Split Capital \& Highly Geared Investment Trusts”, Williams de Broë.

Scott, LO, 1997, "Pricing Stock Options in a Jump-Diffusion Model with Stochastic Volatility and Interest Rates: Applications of Fourier Inversion Methods”, Mathematical Finance, 7, 413424.

\section{Appendix 1}

Comparison of the ZDPs of a hypothetical geared to a hypothetical ungeared trust. Assume that both ZDPs have two years until redemption, and that interest and management fees are charged to the revenue account. The underlying portfolios of investments are identical.

\begin{tabular}{|l|l|l|}
\hline & Ungeared Trust & Geared Trust \\
\hline Total Assets & 100 & 100 \\
\hline Debt & 0 & 50 \\
\hline Final ZDP repayment & 80 & 30 \\
\hline Cover & 1.25 & 1.67 \\
\hline Hurdle Rate (\%) & -10.56 & -10.56 \\
\hline Wipe-Out Rate (\%) & -100.00 & -29.29 \\
\hline
\end{tabular}


Both ZDPs have the same hurdle rate, and the geared trust has a higher cover. However, this does not mean that the geared ZDP is less risky than the ungeared ZDP. The geared ZDP has greater sensitivity to large falls in the underlying portfolio. Assuming both ZDPs trade on a gross redemption yield of $7 \%$, the following chart shows how sensitive each ZDP is to changes in the underlying portfolio:

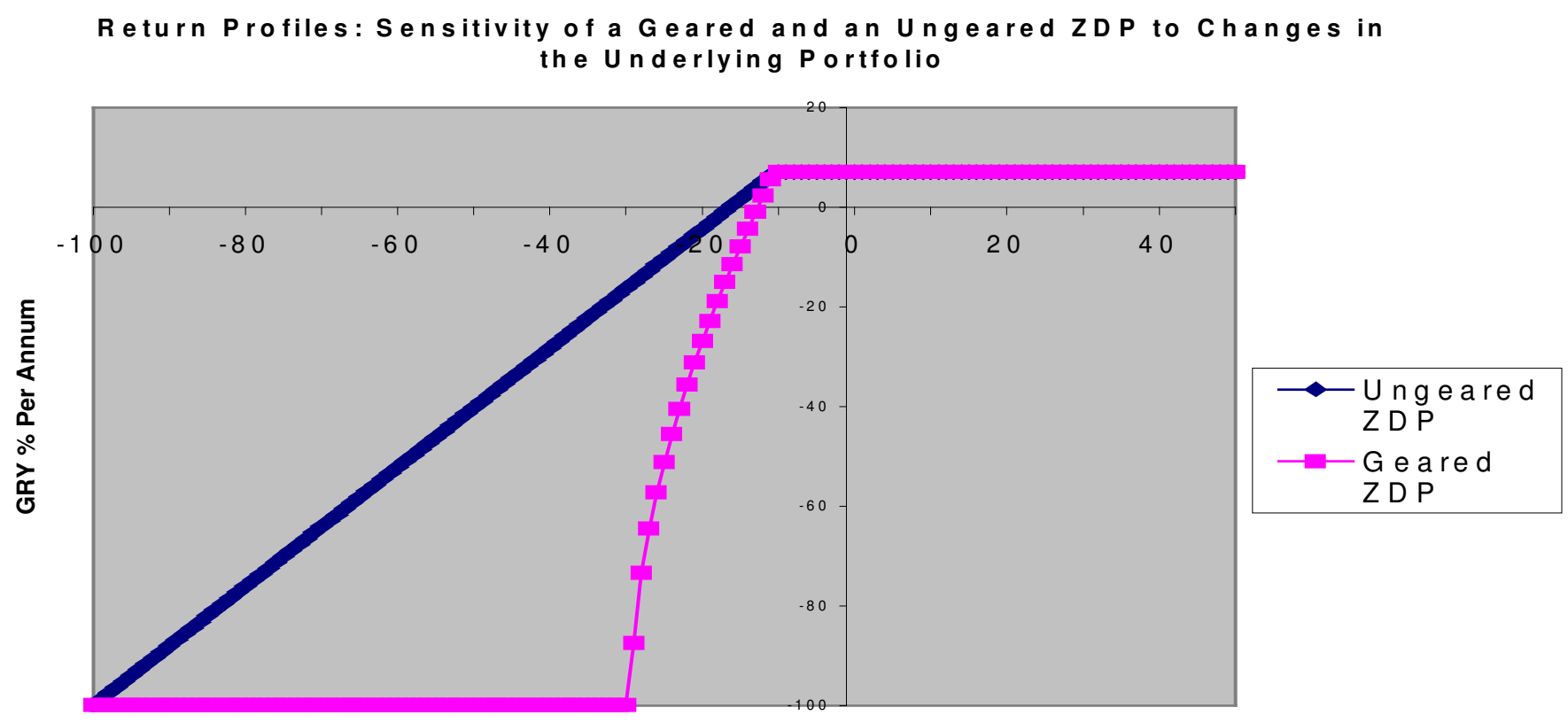

\% Change Per Annum in Underlying Portfolio

\section{$\underline{\text { Appendix } 2}$}

\begin{tabular}{|l|l|}
\hline Rating & Percentage Invested in Splits and High Yield Funds \\
\hline AAA & $0 \%$ \\
\hline AA & $<5 \%$ \\
\hline A & $>5 \%$ but $<25 \%$ \\
\hline B & $>25 \%$ but $<50 \%$ \\
\hline C & $>50 \%$ \\
\hline
\end{tabular}

Source: ABN Amro 


\section{$\underline{\text { Appendix } 3}$}

$\underline{\text { Payoff Chart for Zero Dividend Preference Share }}$

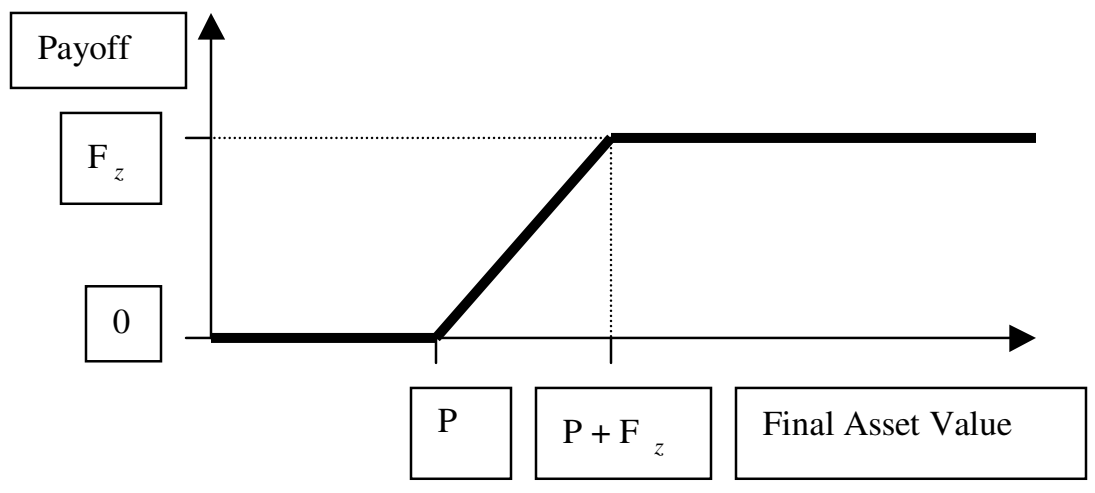

\section{Appendix 4}

Payoff Chart for Income Share

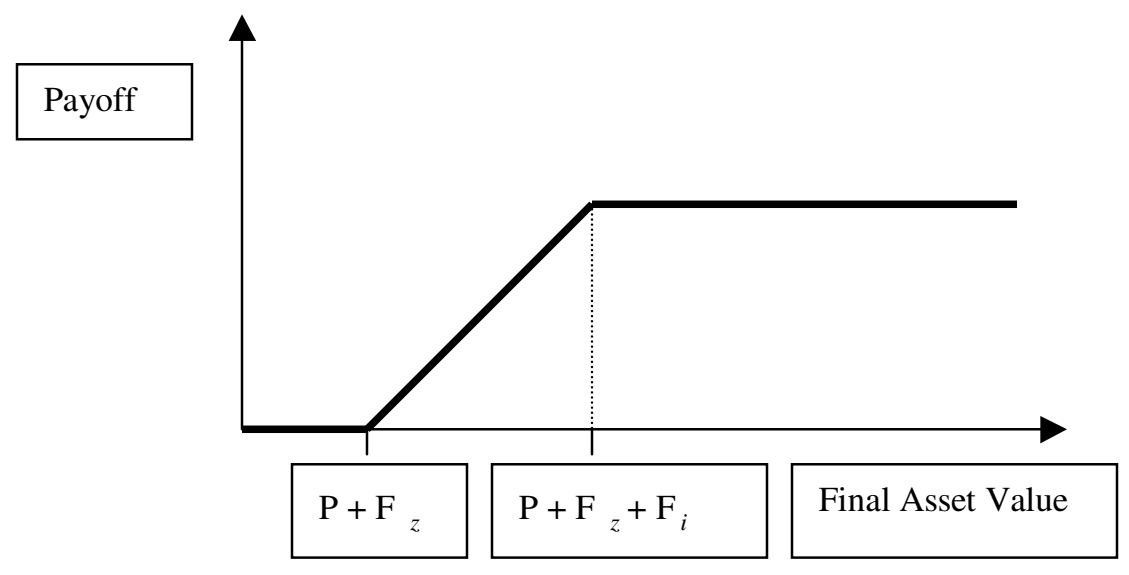




\section{$\underline{\text { Appendix } 5}$}

$\underline{\text { Payoff Chart for Capital Share }}$

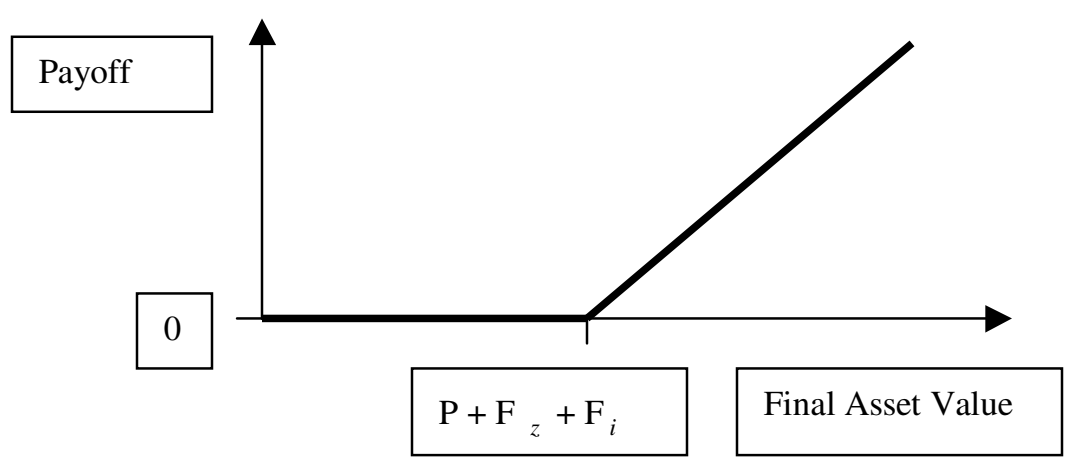

\section{$\underline{\text { Appendix } 6}$}

$\underline{\text { Cumulative Probability Distribution Curve for Gross Assets }}$

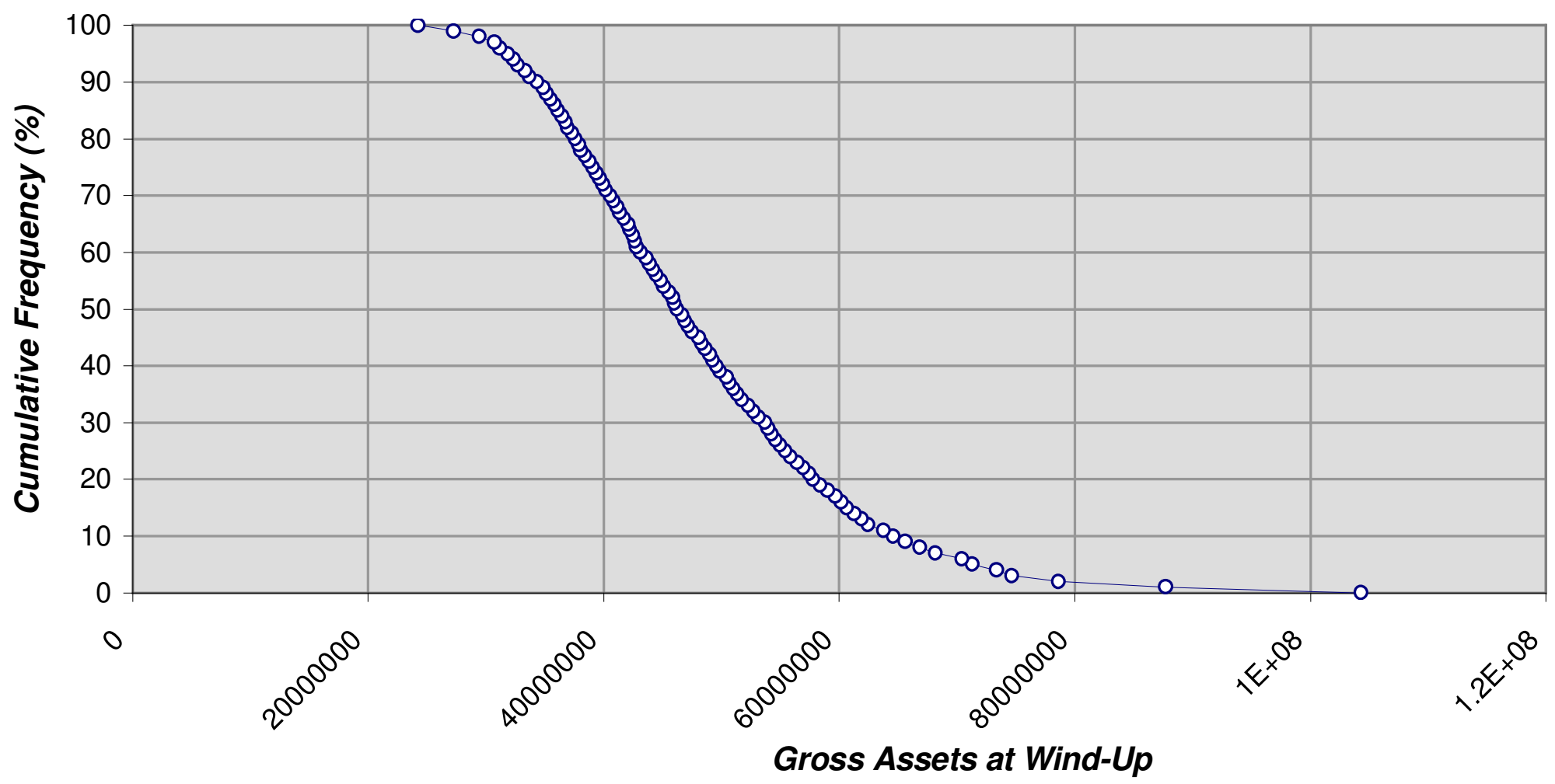




\section{Appendix 7}

Path of Gross Assets at each Stage of the Simulation Process $\left(1^{\text {st }}, 5^{\text {th }}, 25^{\text {th }}, 50^{\text {th }}, 75^{\text {th }}, 95^{\text {th }}\right.$ and $99^{\text {th }}$ percentiles)

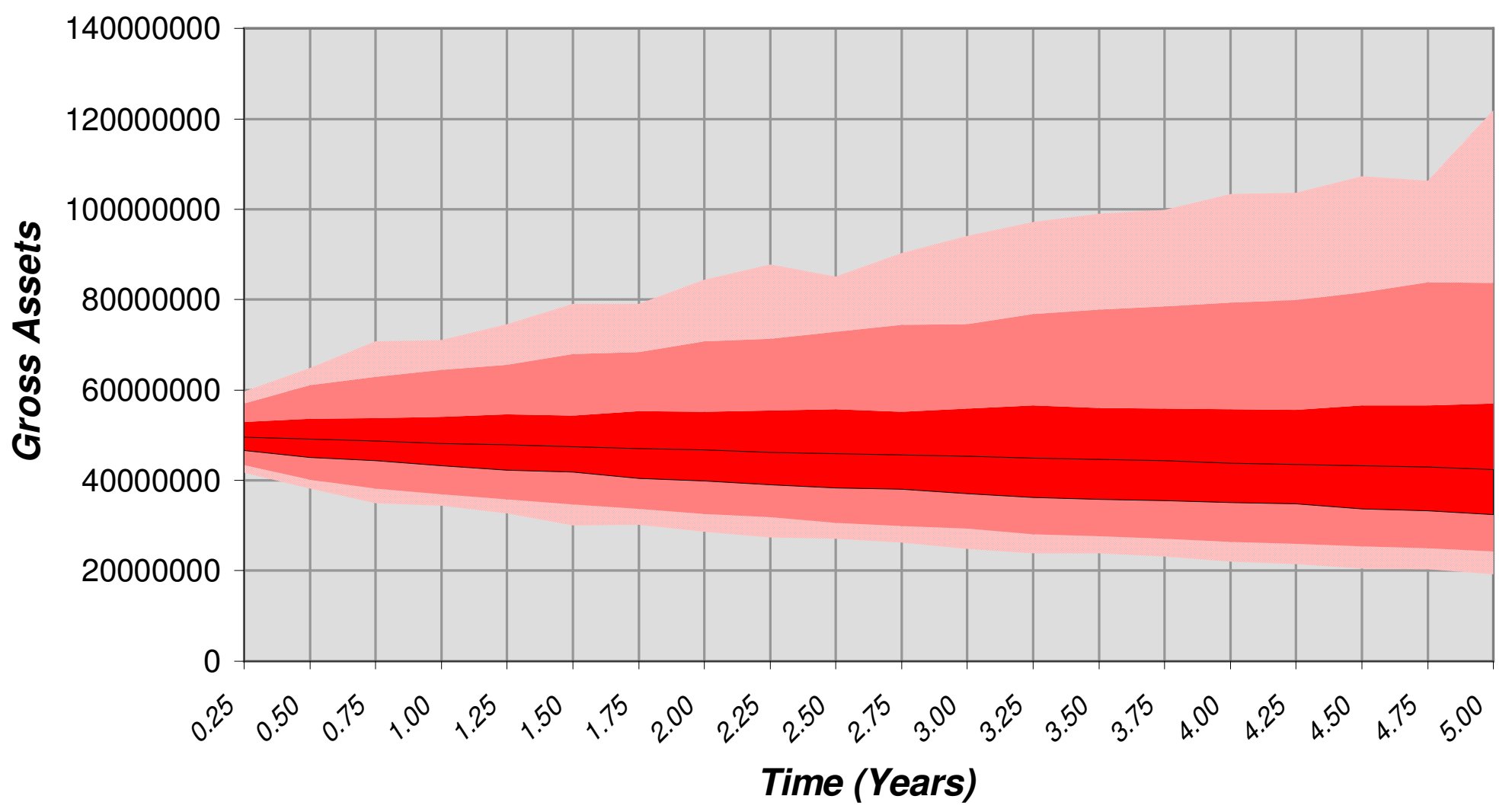

\section{Appendix 8}

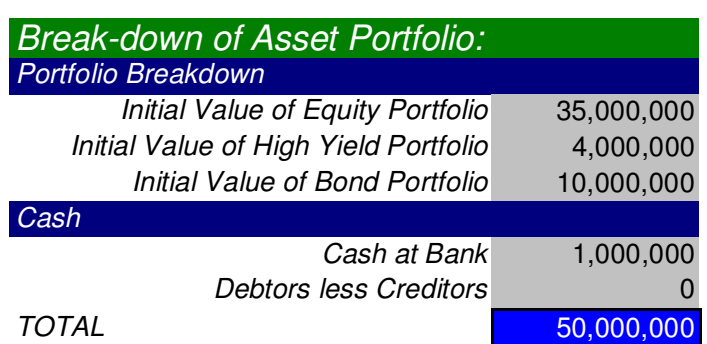

Corporate Bond Portfolio Details

$\begin{array}{rrrrr}\begin{array}{r}\text { Number of Holdings } \\ \text { Coupon Maturity (years) }\end{array} & \begin{array}{r}\text { numholdings } \\ \text { Coupon } \\ \text { Frequency }\end{array} & \begin{array}{r}\text { Credit } \\ \text { Rating }\end{array} & \text { Seniority } \\ 7 \% & 10 & 4 & 3 & 3\end{array}$




\begin{tabular}{|c|c|}
\hline Equity Model & \\
\hline equity risk-premium & $3.5 \%$ \\
\hline volatility & $20.0 \%$ \\
\hline Dividend-yield Model & \\
\hline Dividend yield reversion rate & 0.25 \\
\hline Dividend yield reversion level & -3.02 \\
\hline dividend yield volatility & $20 \%$ \\
\hline initial dividend yield & $3.5 \%$ \\
\hline High-yield Equity Portfolio & \\
\hline beta & 2 \\
\hline stock-specific risk & $10 \%$ \\
\hline dividend yield multiple & 2 \\
\hline
\end{tabular}

\begin{tabular}{|c|c|c|c|c|}
\hline \multicolumn{5}{|l|}{ Classes of Capital } \\
\hline Name of Capital Class & Bank Loans & ZDPs & Income Shares & $\begin{array}{l}\text { Capital } \\
\text { Shares }\end{array}$ \\
\hline Income entitlement & TRUE & FALSE & TRUE & FALSE \\
\hline Capital entitlement & TRUE & TRUE & TRUE & TRUE \\
\hline Capital priority & 1 & 2 & 3 & 4 \\
\hline Nominal or loan amount / Number of shares & $5,000,000$ & $20,000,000$ & $20,000,000$ & $10,000,000$ \\
\hline Fixed income payment per nominal / share (£ pa) & 0.07 & & 0.08 & \\
\hline Fixed capital payment per nominal / share (£) & 1 & 1.8 & 1 & \\
\hline
\end{tabular}

